\title{
Transducing Phages for Bacillus subtilis
}

\author{
By I. TAKAHASHI \\ Microbiology Research Institute, Research Branch, Canada Department \\ of Agriculture, Ottawa, Canada
}

(Received 3 September 1962)

SUMMARY

Transducing phage PBS1 and a clear-plaque type mutant PBS2 derived from PBS 1 show similar growth characteristics with a relatively small burst size ( 23 to 24), and are related serologically. They are morphologically indistinguishable and both have a dense head of about $100 \mathrm{~m} \mu$ in diameter and a tail about $250 \mathrm{~m} \mu$ in length. PBS 1 is more efficient in transduction and its plaque-forming activity is more sensitive to ultraviolet (u.v.) irradiation than that of PBS 2. The host range of the phages is limited to strains of Bacillus subtilis. All Marburg strains tested were sensitive to thely tic action of the phages. Prophages of PBS 1 and PBS 2 were not u.v.inducible and the irradiation of lysogenic cultures with a relatively high dose of u.v. radiation resulted in considerable decrease of the free phage titre. However, transducing activities of lysates treated with a high dose of u.v. radiation were not affected significantly. Organisms lysogenic either for PBS 1 or to PBS2 were not stable and reverted to the sensitive state.

\section{INTRODUCTION}

It has been shown that the temperate phage PBS 1 is capable of transducing a number of genetic traits in Bacillus subtilis (Takahashi, 1961). A clear-plaque type mutant (PBS2) derived from PBS 1 is also able to carry out general transduction, although the frequency of transduction is always lower than that of PBS 1. Thorne (1961) also isolated a temperate phage from soil and demonstrated transduction in the same organism. However, the phages reported here differ in host range and other properties from the temperate phages for $\boldsymbol{B}$. subtilis reported hitherto (Romig $\&$ Brodetsky, 1961; Thorne, 1962). This paper describes the general characteristics of transducing phages PBS1 and PBS2.

\section{METHODS}

The bacterial strains used in this work are listed in Table 1. Organisms grown overnight on Difco Tryptose Blood Agar Base (TBB agar) were used as inoculum. Soft TBB agar was made up to contain the same ingredients as the prepared product with the exception that the agar content was $1 \%$. As the Bacillus subtilis strains used sporulated poorly on TBB agar, inocula were essentially all vegetative forms. Liquid cultures were obtained by growing the organisms in Penassay Broth (Difco) with shaking for $4 \mathrm{hr}$. The sporulation medium of Schaeffer (1961) was used to obtain spores. Medium Y (Cook \& Lochhead, 1959) was used as diluent in the assay of plaque-forming particles. All incubations were at $37^{\circ}$ unless otherwise stated. 
Phages were isolated from soil samples collected at various places in Ottawa by a modification of the method described by Ivanovics \& Lantos (1958). Samples of cultivated soil (about $50 \mathrm{~g}$.) were suspended in $\mathbf{5 0} \mathrm{ml}$. tap water containing a small number (about $10^{7}$ ) of streptomycin-resistant indicator bacteria Bacillus subtilis SB 19. After 2 days at room temperature the soil suspensions were shaken vigorously and allowed to settle for $30 \mathrm{~min}$. A sample of supernatant liquid was mixed with an equal volume of medium $\mathrm{Y}$ and shaken for $3 \mathrm{hr}$. To a $10 \mathrm{ml}$. portion of the mixture were added $5 \mathrm{ml}$. of indicator culture and streptomycin sulphate (Mann Research Laboratories, Inc.) to a final concentration of $500 \mu \mathrm{g} . / \mathrm{ml}$., and incubation continued for a further $6 \mathrm{hr}$. with shaking. The number of plaque-forming particles in the culture was determined, after a brief centrifugation, on soft agar containing streptomycin sulphate $500 \mu \mathrm{g} . / \mathrm{ml}$.

Since the soft agar-layer method of Adams (1959) did not give satisfactory results in the assay of PBS 1, the following modification of the pre-adsorption technique of Potter \& Nelson (1952) was used. Three ml. samples of lysate diluted in medium $Y$ were mixed in sterile test tubes $(16 \times 125 \mathrm{~mm}$.) with $1.5 \mathrm{ml}$. medium $\mathrm{Y}$ containing about $5 \times 10^{7}$ indicator bacteria. After $5 \mathrm{~min}$. at room temperature $4.5 \mathrm{ml}$. of soft TBB agar (previously melted and kept in a $55^{\circ}$ water bath) were added to the tubes with a $10 \mathrm{ml}$. graduated pipette (large tip opening) and mixed thoroughly. Fresh TBB agar plates were overlaid with $3 \mathrm{ml}$. samples of this phage + bacteria mixture. By this modified technique the number of plaques that developed on each plate represented the number of plaque-forming particles $/ \mathrm{ml}$. lysate tested. The assay plates were made in duplicate. The soft agar plates were incubated overnight at $28^{\circ}$. The omission from medium $\mathbf{Y}$ of yeast extract and ferric chloride decreased the plaque counts by about $80 \%$. Under the same condition the adsorption of phage to host bacteria was also decreased to the same extent. Thus the low plaque counts observed were probably due to poor adsorption of phage to host.

Phage lysates were made by the following technique. Phage-sensitive cultures in Penassay Broth in the logarithmic growth phase were infected with phage at a multiplicity of infection of about $\mathbf{1 . 0}$ and shaken for one additional hour. The infected cultures were further incubated overnight without shaking. After a brief centrifugation at low speed, the lysates were filtered through Millipore filter membranes $(0 \cdot 45 \mu$ pore size). Lysates were also made by growing lysogenic cultures in Penassay Broth for $4 \mathrm{hr}$. with shaking, followed by overnight incubation without shaking. Plaque counts of lysates made by either methods were about $5 \times 10^{9} / \mathrm{ml}$. for PBS 1 and $5 \times 10^{9}$ to $1 \times 10^{10}$ for PBS 2.

Ultraviolet irradiations of lysogenic cultures and phages were carried out at a distance of $20 \mathrm{~cm}$. from a 'Mineralight' source (Ultraviolet Products Inc., South Pasadena, California) equipped with a $2537 \AA$ filter.

Procedures for the transduction experiments were as previously described (Takahashi, 1961). In initial experiments, recipient organisms were grown in minimal media supplemented with growth factors. Higher frequencies of transduction, however, were obtained when the organisms were grown in a complex medium such as Penassay Broth. 


\section{RESULTS}

Phage isolates. By using the method described it was possible to isolate, from 12 of 15 soil samples, phages active on Bacillus subtilis at a titre of $10^{2}$ to $10^{4}$ particles/ $\mathrm{ml}$. Among the phage isolates, temperate phage PBS 1 was able to transduce prototrophy, resistance to antibiotics (streptomycin, erythromycin, neomycin) and sporogenesis in strains of $\boldsymbol{B}$. subtilis.

When a large number of particles of phage PBS 1 were plated on soft agar with Bacillus subtilis SB 19 as indicator, the presence of clear plaques which were distinct from those of PBS1 was noted. This clear-plaque type mutant (PBS2) was also temperate and able to carry out general transduction in $\boldsymbol{B}$. subtilis, although the frequency of transduction was lower than that with phage PBS 1.

Plaque morphology. Plate 1, figs. 1, 2, show the plaque morphology of phages PBS 1 and PBS 2. PBS 1 forms turbid plaques of about $1 \mathrm{~mm}$. in diameter with peripheral rings. PBS 2 forms clear plaques of about $1 \mathrm{~mm}$. in diameter which become slightly turbid after prolonged incubation.

Morphology of the phage particles. Electron micrographs were prepared by the pseudo-replica technique described by Wyckoff (1951). Phages PBS 1 and PBS 2 were almost indistinguishable in their morphology (Pl. 1, figs. 3, 4). They were spermlike with a dense head (about $100 \mathrm{~m} \mu$ diameter) and tail (about $250 \mathrm{~m} \mu$ length). These dimensions are comparable to those of $\mathrm{T} 4$ phage which is one of the largest phages described (Luria, 1962).

Serology. Rabbit antisera were made and their velocity constants (K) of neutralization were measured according to the procedures of Adams (1959). An antiserum made against phage PBS 1 having a $K$ value of 1830 had a $K$ value of 810 when measured against phage PBS2. It was found that the lysates of PBS 1 and PBS2 contained, with different proportions, four density species determined in the $\mathrm{CsCl}$ density gradient; one was purely transducing and had no plaque-forming activities (unpublished results). This suggests that phage particles in the lysates of PBS 1 and PBS2 are not homogeneous. Therefore, the difference in the rate of inactivation observed here may not be significant, since the $K$ values were calculated only by the decrease in the number of plaque-forming particles. Nevertheless, the results obtained indicate that the two phages are closely related serologically.

Host range. The host range of the phages was determined by spotting a drop of cell-free lysate on a soft agar layer seeded with test organisms. Table 1 shows the results of host range determinations made with several aerobic spore-forming bacteria belonging to different groups. The Marburg strain of Bacillus subtilis and all its derivatives were susceptible to the lytic action of phages PBS1 and PBS2, and general transduction could be performed between these strains. Although other $B$. subtilis strains isolated from various sources were sensitive to the phages, attempts to transduce a streptomycin marker to these strains with $B$. subtilis SB 19 as donor did not succeed.

Growth characteristics. Single-step growth experiments were made according to the procedures described by Adams (1959). The results obtained with Bacillus subtilis SB 19 as host are summarized in Table 2. Phages PBS 1 and PBS2 both have a relatively small burst size and their growth characteristics are very similar. In the same experiments, from viable counts made on infected and uninfected 
bacteria, it was found that only $15 \%$ of bacteria which were killed by phage PBS 1 gave rise to plaques. The proportion of plaque formers among bacteria infected by phage PBS 2 was higher (35\%). This observation suggests the presence in the lysates of defective particles which kill the host bacteria but do not initiate phage multiplication. These resemble 'killer particles' found in defective lysogenic transductants of Shigella dysenteriae (Luria, Adams \& Ting, 1960).

Table 1. Susceptibility of species of Bacillus to phages PBS 1 and PBS 2

\begin{tabular}{|c|c|c|c|c|}
\hline & & & Lysis 1 & hage* \\
\hline Bacillus & & Source of culture & PBS 1 & PBS 2 \\
\hline 3. subtilis & & NCTC 3329 & - & - \\
\hline & & NCTC 2586 & + & + \\
\hline & & ATCC 6633 & + & + \\
\hline & Marburg & ATCC 6051 & + & + \\
\hline & SB 19 & $\begin{array}{l}\text { Dr E. W. Nester } \\
\text { (Stanford University) }\end{array}$ & + & + \\
\hline & Wild type & $\begin{array}{l}\text { Dr J. Spizizen (University } \\
\text { of Minnesota) }\end{array}$ & + & + \\
\hline & 168 & $\begin{array}{l}\text { Dr J. Spizizen (University } \\
\text { of Minnesota) }\end{array}$ & + & + \\
\hline B. subtilis var. niger $\dagger$ & & & + & + \\
\hline B. megaterium & & MRI† 151 & - & - \\
\hline B. brevis & & MRI 515 & - & - \\
\hline B. circulans & & MRI 602 & - & - \\
\hline B. sphaericus & & MRI 566 & - & - \\
\hline B. cereus & & MRI 247 & - & - \\
\hline B. cereus & & MRI 818 & - & - \\
\hline B. thuringiensis var. thuringiensis & & Dr D. Kushner (NRC)§ & - & - \\
\hline B. thuringiensis var. alesti & & Dr D. Kushner (NRC) & - & - \\
\hline B. polymyxa & & ATcc7070 & - & - \\
\hline
\end{tabular}

$*+=$ lysis ; - = lack of lysis ; $\dagger$ determined by Dr J. Marmur, Brandeis University ; $\ddagger$ MRI: Microbiology Research Institute, Ottawa; NRC: § National Research Council of Canada, Ottawa.

Table 2. Growth characteristics of phages PBS 1 and $P B S 2^{*}$

Host: Bacillus subtilis SB 19

$\begin{array}{lccc}\text { Phage } & \begin{array}{c}\text { Latent period } \\ \text { (min.) }\end{array} & \begin{array}{c}\text { Rise period } \\ \text { (min.) }\end{array} & \text { Burst size } \\ \text { PBS 1 } & 35 & 15 & 23 \\ \text { PBS 2 } & 37 & 18 & 24\end{array}$

* Averages of 4 experiments for each phage.

Stability of the phages. The phages PBS1 and PBS2 appear to be fairly stable when stored at $5^{\circ}$. Plaque counts decreased only about $50 \%$ when lysates of phages PBS 1 or PBS 2 were stored at $5^{\circ}$ for 3 months. No measurable decrease in phage titre was noted when lysates were treated with chloroform. The transducing activity in lysates, on the other hand, declined at a much faster rate under the same conditions. In a typical experiment, the number of indole ${ }^{+}$colonies developing from Bacillus subtilis 168 (indole ${ }^{-}$) when treated with $0 \cdot 1 \mathrm{ml}$. of lysates made from $\boldsymbol{B}$. subtilis SB 19 decreased from 3500 to 510 after 3 months at $5^{\circ}$, while the plaque count of phage PBS 1 decreased from $6 \cdot 8 \times 10^{8} / \mathrm{ml}$. to $3 \cdot 8 \times 10^{8} / \mathrm{ml}$.

Stability of lysogenic cultures. It was reported that stably lysogenic bacteria could be isolated from turbid plaques formed by phage PBS1 (Takahashi, 1961). The 
lysogenic cultures retained their prophage through repeated subcultures on sporulation agar and heating at $85^{\circ}$ for $15 \mathrm{~min}$. Control experiments showed that the same heat treatment decreased the phage titre of a lysate from $10^{7} / \mathrm{ml}$. to $<1 / \mathrm{ml}$. It was found, however, that the individual lysogenic bacteria were not quite as stable as previously thought. When about 100 colonies derived from heated spores of Bacillus subtilis SB 19 lysogenic for phage PBS1 were examined, 50\% of them were found to be in the typical lysogenic state while the remainder were immune to phage infection but had lost their ability to produce free phage. This at first suggested that the immune state was intermediate between sensitivity and lysogeny. However, in further experiments when a colony of lysogenic B. subtilis SB19 was grown in Penassay Broth containing phage antiserum at $1 / 500$ ( $\mathrm{K}$ value of the serum estimated at a dilution of $1 / 2000$ being 1830) for $4 \mathrm{hr}$. and plated on TBB agar, $30 \%$ of the colonies were fully lysogenic and the remainder were sensitive, there being no detectable colonies of the immune type. The necessity for postulating the intermediate state was thus eliminated since, during the initial growth of lysogenic $B$. subtilis SB 19 in the absence of phage antiserum, the presence of a large number of free phages could have served to eliminate sensitive bacteria and to select resistant (immune) bacteria derived from them. Bacteria lysogenic for phage PBS 2 were also unstable and eventually reverted to the sensitive state. Because of this instability of the lysogenic state, it was not possible to establish any exact relationship between transduction and lysogenization.

Induction by $u . v$. irradiation. Attempts to induce phage development by u.v. irradiation of lysogenic bacteria were unsuccessful. The bacteria were irradiated in physiological saline with a 30-95\% killing dose of u.v. radiation and transferred into Penassay Broth. At a relatively low dose of u.v. radiation in no case was there an appreciable increase in phage titre when compared with unirradiated cultures. Both irradiated and unirradiated lysogenic cultures gave a titre of about $10^{9} / \mathrm{ml}$. after they were incubated overnight without shaking. Relatively high doses of u.v. radiation ( $95 \%$ killing) decreased the free phage titre by about $90 \%$.

\section{Table 3. Effect of u.v. irradiation on plaque count and transducing activity of phage PBS 1}

Recipient: Bacillus subtilis $168\left(\right.$ ind $\left.^{-}\right)$. B. subtilis W-ery (prototrophic and resistant to $1 \mu \mathrm{g} . / \mathrm{ml}$. of erythromycin) was used as donor.

$\begin{array}{cclcc}\begin{array}{c}\text { Dose of u.v. } \\ \text { irradiation } \\ \text { (sec.) }\end{array} & \begin{array}{c}\text { Plaque } \\ \text { count/ml. }\end{array} & \begin{array}{l}\text { Fraction } \\ \text { surviving }\end{array} & \begin{array}{c}\text { Prototrophs* } \\ \text { (recipient:168) }\end{array} & \begin{array}{c}\text { Erythromycin } \\ \text { resistant colonies* } \\ \text { (recipient:168) }\end{array} \\ 0 & \mathbf{3 . 6 \times 1 0 ^ { 9 }} & 1 \cdot 0 & 850 & 1400 \\ 20 & 5 \cdot 4 \times 10^{8} & 0 \cdot 15 & 630 & 1750 \\ 40 & \mathbf{7 . 5} \times 10^{7} & 0 \cdot 021 & 870 & 1570 \\ 80 & 9.5 \times 10^{6} & 0 \cdot 0026 & 1020 & 1640 \\ 120 & 2 \cdot 1 \times 10^{6} & 0.00058 & 1570 & 1470\end{array}$

* Number of transductants developed from $0.1 \mathrm{ml}$. of lysates and $0.9 \mathrm{ml}$. of recipient culture.

Effect of u.v. irradiation on the phages. Cell-free lysates were treated with various doses of u.v. radiation in very thin layers in Petri dishes which were agitated continuously. The plaque counts and transducing activities of the irradiated lysates are shown in Tables 3 and 4. Exponential decreases in the plaque count of phages 
PBS 1 and PBS 2 were obtained up to 40 sec. exposure; thereafter, the inactivation proceeded at a somewhat lower rate. The lytic activity of phage PBS 2 was more resistant to u.v. irradiation than that of phage PBS 1. On the other hand, the transducing activity was apparently unaffected; it doubled for the indole marker even though the plaque count was decreased from $10^{9} / \mathrm{ml}$. to $10^{6} / \mathrm{ml}$.

\section{Table 4. Effect of u.v. irradiation on plaque count and transducing activity of phage $\mathrm{PBS} 2$}

Recipients: Bacillus subtilis $168\left(\right.$ ind $\left.^{-}\right)$; B. subtilis S10. B. subtilis SB 19 (prot, str-r) was used as donor. S10 was derived from the wild type strain of Spizizen (see Table 1) by u.v. irradiation and was glutamic acid-'.

\begin{tabular}{|c|c|c|c|c|}
\hline $\begin{array}{l}\text { Dose of u.v. } \\
\text { radiation } \\
\text { (sec.) }\end{array}$ & $\begin{array}{l}\text { Plaque } \\
\text { count } / \mathrm{ml} \text {. }\end{array}$ & $\begin{array}{r}\text { Fraction } \\
\text { surviving }\end{array}$ & $\begin{array}{r}\text { Prototrophs* } \\
\text { (recipient:168) }\end{array}$ & $\begin{array}{c}\text { Prototrophs* } \\
\text { (recipient:S 10) }\end{array}$ \\
\hline 0 & $2.7 \times 10^{9}$ & $1 \cdot 0$ & 390 & 260 \\
\hline 20 & $5.3 \times 10^{8}$ & $0 \cdot 19$ & 380 & 230 \\
\hline 40 & $1.4 \times 10^{8}$ & 0.051 & 550 & 190 \\
\hline 80 & $2.7 \times 10^{7}$ & $0 \cdot 010$ & 630 & 230 \\
\hline 120 & $6.1 \times 10^{6}$ & 0.0022 & 840 & 260 \\
\hline
\end{tabular}

* Number of transductants developed from $0.1 \mathrm{ml}$. of lysates and $0.9 \mathrm{ml}$. of recipient culture.

\section{DISCUSSION}

The host ranges of phages PBS1 and PBS2 seem to be restricted to certain strains of Bacillus subtilis, while the temperate phage SP 13 for B. subtilis isolated by Romig \& Brodetsky (1961) is active on several Bacillus species, including $B$. megaterium and $B$. brevis. Thorne (1962) reported that his transducing phage SP 10 was active on $B$. subtilis W23 and its derivatives but had no lytic activity on $B$. subtilis 168, although this strain can be used as recipient in transduction. As shown in Table 1, phages PBS1 and PBS2 form plaques on $B$. subtilis 168 as well as on other derivatives of the Marburg strain. This difference in host range may be explained by the fact that phage SP10 was isolated with $B$. subtilis W 23 as indicator and, in the present report, $B$. subtilis SB 19 was used for the isolation of phage PBS1. B. subtilis SB 19 is a prototrophic derivative of $B$. subtilis 168 obtained by transformation with deoxyribonucleic acid (DNA) prepared from B. subtilis 23 (Nester \& Lederberg, 1961) and presumably still possesses the genetic background of B. subtilis 168. Moreover, buoyant densities of the DNA prepared from phages PBS 1 and SP10 are quite different from each other (Dr J. Marmur, personal communication). It appears, therefore, that phage PBS 1 belongs to a phage race which is distinct from phages SP10 or SP13, although they are all temperate.

Unexpectedly, during the single-step growth experiments, it was found that only a small portion of bacteria killed by the phage infection were able to form plaques. Lysates containing phage PBS 1, therefore, seem to contain defective particles as well as plaque-forming particles. At present the nature of these killing particles and their relations to the transducing particles are not known. Investigations are being undertaken to clarify this situation.

Garen \& Zinder (1955) reported that the transducing activity of phage P22 for Salmonella typhimurium was not significantly depressed by a high dose of u.v. radiation; similar observations have been made with phages PBS1 and PBS 2. 
Presumably the transducing activity of these phages also involves only a small portion of u.v.-sensitive material (DNA) of the phages.

The author wishes to thank Dr J. Marmur for supplying unpublished information. The capable technical assistance of $\mathbf{M r}$ W. A. Webster is gratefully acknowledged.

Contribution no. 539 from Microbiology Research Institute, Research Branch, Canada Department of Agriculture, Ottawa, Canada.

\section{REFERENCES}

Adams, M. H. (1959). Bacteriophages. New York: Interscience Publishers.

Cook, F. D. \& LochHEAD, A. G. (1959). Growth factor relationships of soil microorganisms as affected by proximity to the plant root. Canad. J. Microbiol. 5, 323.

Garen, A. \& Zinder, N. D. (1955). Radiological evidence for partial genetic homology between bacteriophage and host bacteria. Virology, 1, 347.

Ivanovics, G. \& Lantos, J. (1958). An effective method for isolation of anthrax phages. Acta microbiol. Acad. Sci. hung. 5, 405.

Luria, S. E., Adams, J. N. \& Ting, R. C. (1960). Transduction of lactose-utilizing ability among strains of $E$. coli and $S$. dysenteriae and the properties of the transducing phage particles. Virology, 12, 348.

Luria, S. E. (1962). Bacteriophage genes and bacterial function. Science, 136, 685.

Nester, E. W. \& Lederberg, J. (1961). Linkage of genetic units of Bacillus subtilis in DNA transformation. Proc. nat. Acad. Sci., Wash. 47, 52.

Potter, N. N. \& Nelson, F. E. (1952). Effects of calcium on proliferation of lactic streptococcus bacteriophage. J. Bact. 64, 105.

Romig, W. R. \& BRoDETSky, A. M. (1961). Isolation and preliminary characterization of bacteriophages for Bacillus subtilis. J. Bact. 82, 135.

Schaeffer, P. (1961). Étude génétique, biochimique et cytologique de la sporulation de Bacillus subtilis. D.Sc. thesis, Faculty of Science, University of Paris.

Takahashi, I. (1961). Genetic transduction in Bacillus subtilis. Biochem. Biophys. Res. Comm. 5, 171.

Thorne, C. B. (1961). Transduction in Bacillus subtilis. Fed. Proc. 20, 254.

Thorne, C. B. (1962). Transduction in Bacillus subtilis. J. Bact. 83, 106.

WyскоғF, R. W. G. (1951). Electron microscopy of developing bacteriophage and other viruses. Prog. Biophys. biophys. Chem. 2, 224.

\section{EXPLANATION OF PLATE 1}

Fig. 1. Plaques formed on Bacillus subtilis SB 19 by phage PBS1. $\times 5$.

Fig. 2. Plaques formed on $B$. subtilis SB 19 by phage PBS $2 . \times 5$.

Fig. 3. Electron photomicrograph of phage PBS 1. $\times 11,000$.

Fig. 4. Electron photomicrograph of phage PBS 2. $\times 11,000$. 
Journal of General Microbiology, Vol. 31, No. 2

Plate 1

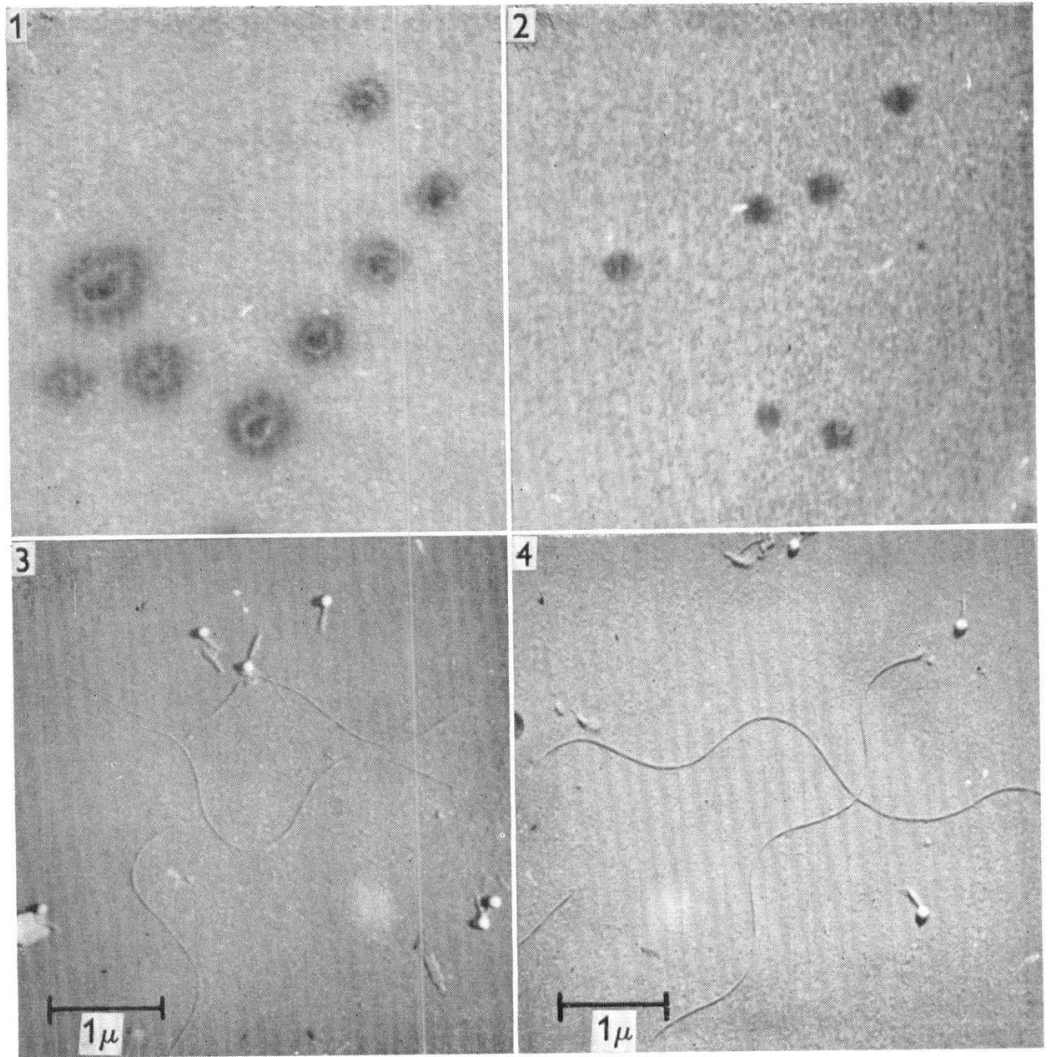

